\title{
Propofol induced severe neuroexcitatory symptoms during emergency laparotomy
}

\author{
Puneet K. Banga*, Shalini Dadu, Madhuri Sharma
}

\begin{abstract}
Department of Anesthesiology and Critical Care, Shri Guru Ram Rai Institute of Medical and Health Sciences, Patel Nagar, Dehradun-248001, India
\end{abstract}

Received: 1 July 2013

Accepted: 21 July 2013

*Correspondence to:

Dr. Puneet K. Banga,

Email:

drpuneetbanga24@gmail.com

(C) 2013 Banga PK et al. This is an open-access article distributed under the terms of the Creative Commons

Attribution Non-Commercial License, which permits unrestricted non-commercial use, distribution, and reproduction in any medium, provided the original work is properly cited.

\begin{abstract}
Propofol is a widely used intravenous agent for general anesthesia and sedation. Propofol is associated with a variety of neuroexcitatory events including: opisthotonus, muscle rigidity, myoclonus, and seizures collectively termed as seizure-like phenomenon (SLP). We report a rare case of propofol induced severe neuroexcitatory symptoms at the time of induction in a young male presenting for emergency laparotomy. He developed generalized tonic- clonic seizures which resulted in dislodgement of intravenous cannula. Immediately a new intravenous cannula was inserted with difficulty during convulsions and injection thiopentone $200 \mathrm{mg}$ bolus was given. Convulsions subsided within a minute. Patient remained hemodynamically stable and surgery was uneventful. He developed emergence agitation which was treated with injection midazolam. Patient recovered with no neurologic sequelae.
\end{abstract}

Keywords: Propofol, Seizures, Neuroexcitatory symptoms

\section{INTRODUCTION}

Many anesthetic drugs have been reported to induce seizures clinically, but most of these drugs also have anticonvulsant properties. ${ }^{1,2}$ Despite the claims of proconvulsant activity of propofol, there is also evidence of its anticonvulsant action. ${ }^{3-5}$ Severe neuroexcitatory symptoms are rare side effect of propofol which can occur during the induction, maintenance or emergence from anesthesia. ${ }^{6}$ We present one such case of severe neuroexcitatory symptoms after induction with propofol which was managed with injection thiopentone and midazolam. This report stresses on the importance of rare and serious complication associated with propofol with an incidence of less than one percent.

\section{CASE REPORT}

A 30 year old male presented to emergency department with abdominal pain. The patient had no previous medical, surgical history, no history of epilepsy and drug abuse. His routine blood and urine investigations were within normal limits. A diagnosis of perforation peritonitis was made on the basis of abdominal X-ray and ultrasonography. An emergency laparotomy was planned. In the operating room monitoring included ECG, pulse oximetry, noninvasive blood pressure and capnography. Patient was preoxygenated and injection fentanyl $100 \mu \mathrm{g}$ was administered slowly. Anesthesia was induced with injection propofol $120 \mathrm{mg}$ slowly (contain preservative free lidocaine). Immediately he developed generalized tonic-clonic seizures with increased tone in extensor muscle of neck leading to hyperextension of head. Intense jerky movements resulted in dislodgement of intravenous cannula. Patient was about to fall from the operation theatre table. Operation theatre assistants had to hold the patient to stabilize him during seizures and we inserted a new cannula with difficulty. Immediately injection thiopentone $200 \mathrm{mg}$ was administered. Seizures subsided within a minute. Then trachea was intubated 
after achieving neuromuscular blockade with injection vecuronium bromide. Throughout the surgery patient remained hemodynamically stable. Neuromuscular blockade was reversed and trachea was extubated when he became conscious. Patient developed emergence agitation which was treated with intravenous injection of $2 \mathrm{mg}$ midazolam. He became normal within ten minutes. Postoperative blood investigation, neurological examination and computerized tomographic scanning of head were normal.

\section{DISCUSSION}

Propofol is a rapid onset and short acting intravenous anesthetic agent. It has been widely used for anesthesia and sedating patients in intensive care units. Common side effects of propofol are hypotension, dose dependent respiratory depression and burning pain during injection. Neuroexcitatory symptoms including generalized tonicclonic seizures, focal motor seizures, increased muscle tone, myoclonus and opisthotonus are rare and potentially harmful side effect of propofol. ${ }^{7,8}$ These neuroexcitatory symptoms can dislodge laryngeal mask airway, intravenous cannula and may injure the patients. Insertion of new cannula is difficult at the time of seizures in these patients and can pose a problem to give intravenous drug to control seizures. These symptoms occur mostly at the time of induction and during emergence. Rapid change in the propofol concentration in the brain may be crucial for the generation of seizures. Delayed onset seizures have also been reported following propofol anesthesia and after sedation with propofol in intensive care. ${ }^{10}$ These side effects seldom produce neurologic sequelae.

Pathophysiological mechanisms underlying the neuroexcitatory symptoms associated with propofol are unknown but several theories have been proposed. Propofol induces an imbalance between excitatory and inhibitory pathway in brain. Neuroexcitatory symptoms can be caused by an imbalance between cortical and subcortical structures as well as decreased inhibitory output from the formatio reticularis. Propofol has strychnine like effect on glycenergic and GABAergic pathways. Animal model suggest that antagonism of glycine receptors for strychnine to the cerebral cortex evokes epileptiform phenomena.

As combination of drugs were administered during anesthesia, so there is a possibility of other coadministered drugs to produce seizures. Reports of generalized tonic-clonic seizures after use of fentanyl are there but patients treated with higher dose of fentanyl may fail to produce seizures. Lidocaine can produce seizures in toxic dose. But the dose of lidocaine which is given with propofol is much less. However the frequent reported association between seizures and propofol, with normal serum electrolytes and neurological assessment in our case probably made the propofol the most likely cause.

Despite several case reports and systemic review, there is no clear consensus regarding risk factors, prevention and management of such adverse events. Uses of injection thiopentone and benzodiazepines have been reported for its management. We have also used injection thiopentone, a well known anticonvulsant drug, to control the seizures.

Since propofol is routinely used intravenous agent for induction and sedation, especially in day care surgery and in the future probably will be even more common, we would like to stress on the rare and serious complication of propofol - "severe neuroexcitatory symptoms" which needs high vigilance during perioperative period.

\section{Funding: No funding sources \\ Conflict of interest: None declared \\ Ethical approval: Not required}

\section{REFERENCES}

1. Jung SH, Kim TW, Jung KY, Kim JM. A case of propofol-induced seizure-like phenomena. Korean $\mathbf{J}$ Epilepsy Soc 2003;7:51-53.

2. Walder B, Tramer MR, Seeck M. Seizure like phenomenon and Propofol: A systematic review. Neurology 2002;58:1327-32.

3. Baraka A, Aouad M. Is propofol anticonvulsant or proconvulsant? Can J Anaesth 1997;44:1027-9.

4. Hewitt PB, Chu DL, Polkey CE, Binnie CD. Effect of propofol on the electrocorticogram in epileptic patients undergoing cortical resection. Br J Anaesth 1999;82:199-202.

5. Rossetti AO, Reichharty MD, Schaller MD, Despland PA, Bogousslavsky J. Propofol treatment of refractory status epilepticus: A study of 31 episodes. Epilepsia 2004;45:757-63.

6. Reynolds LM, Koh JL. Prolonged spontaneous movement following emergence from propofol/nitrous oxide anesthesia. Anesth Analg 1993;73:192-3.

7. Islander G, Vinge E. Severe neuroexcitatory symptoms after anaesthesia-with focus on propofol anaesthesia. Acta Anaesthesiol Scand 2000;44:144-9.

8. Sutherland MJ, Burt P. Propofol and seizures. Anaesth Intensive Care 1994;22:733-7.

9. Rath GP, Bithal PK, Prabhakar H. Propofol induced myoclonus may dislodge laryngeal mask airway. Indian J Anaesth 2006;50:45-6.

10. Finely GA, MacManus B, Sampson SE, Fernandez CV, Retallick R. Delayed seizures following sedation with propofol. Can J Anaesth 1993:40:863-5.

doi:10.5455/2319-2003.ijbcp20131024

Cite this article as: Banga PK, Dadu S, Sharma M. Propofol induced severe neuroexcitatory symptoms during emergency laparotomy. Int J Basic Clin Pharmacol 2013;2:645-6. 